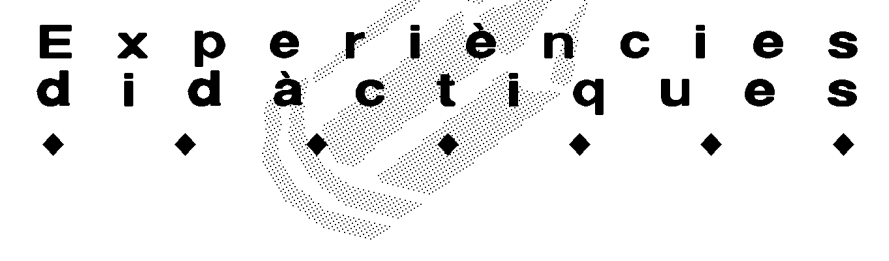

\title{
JOC A JOC, DE PLAÇA A PLAÇA
}

\author{
M. Lourdes Ambrós Ortiz i Trini Ferrús Barbero. Mestres del CEIP Sant Miquel. Ascó. \\ Biel Pubill Soler. Mestre d’Educació Física. IES Flix.
}

\section{Justificació}

No podem obviar que el lloc on, per excel.lència, s'ha desenvolupat el joc popular i tradicional ha estat el carrer, les places i el camp. És per això que sempre que puguem hem d'intentar retrobar aquest món cada cop més perdut i difícil de recuperar com és el del joc al carrer. Fins i tot als pobles, a voltes, ens pot resultar difícil reviure aquelles imatges de fa trenta o quaranta anys en què els nens, individualment o en colles, campaven per l'entramat urbà esplaiant-se en tota mena de jocs.

Conscients d'aquesta realitat, presentem una experiència duta a terme conjuntament entre el CEIP Sant Miquel d'Ascó i I'IES Flix -ambdós centres educatius estan assentats a la Ribera d'Ebre i distanciats $5 \mathrm{~km}-$ en la qual, com es veurà, es va organitzar una activitat basada en la recuperació de diferents jocs tradicionals, preocupant-nos no sols de la part lúdica que del joc es desprèn, sinó també de sensibilitzar l'alumnat de la necessitat de conèixer i dignificar zones del nucli antic del poble i generar dinàmiques de conscienciació, encaminades a valorar la riquesa de qualsevol racó del patrimoni urbà.

\section{Contextualització de l'experiència}

Ascó és un poble de la Ribera d'Ebre de 1600 habitants que, des de la vora mateix de l'Ebre on s'hi emmiralla, s'arrenglera i esglaona a recer d'una muntanya remuntant-la fins a la capçalera on es mantenen, desafiants i orgulloses, les restes d'una construcció defensiva pertanyent al Temple.

El nucli antic o vila closa -com així li agradava anomenar aquesta zona Carmel Biarnés (1981)-, de la qual s'identifiquen diverses estructures i edificacions de principis del segle $\mathrm{XVI}$, dibuixa un traçat laberíntic de carrerons i placetes, amb accessos en ziga-zaga o esglaonats emmarcats sovint en perxes, que esdevenen un marc idoni per recrear situacions de joc.

El joc es va realitzar el divendres 23 de maig de 2003 , de 15 a $17 \mathrm{~h}$ i estava adreçat a un total de 30 alumnes de CS del CEIP Sant Miquel, que van realitzar la gimcana de jocs, i 15 nois i noies de $1 \mathrm{r}$ i $2 \mathrm{n}$ d'ESO de I'IES Flix que van actuar de monitors i dinamitzadors dels jocs.

\section{Objectius i metodologia del projecte}

Des del col.legi pensem que la dinàmica de compartir experiències i fer del joc un eix i un nexe d'unió entre l'escola i l'Institut -al qual aniran properament els nostres alumnes- és molt important, i obre línies de treball i plantejaments interessants tant per a l'alumnat com per al professorat.

Aprofitant la bona sintonia existent entre ambdós centres i la seva proximitat, vam elaborar el projecte JoC a joc, de plaça a plaça tenint com a objectius principals:

- Treballar aspectes relacionats amb l'orientació.

- Conèixer i practicar jocs populars i tradicionals de Catalunya i Espanya, bàsicament de llançament i precisió.

- Reconèixer el context i els escenaris de l'entramat urbà on es realitzaven les formes jugades tradicionals.

- Ser capaç de cooperar amb un grup divers, mixt, amb nens i nenes d'altres nivells.

- Saber escoltar i respectar les explicacions i la informació tramesa per altres nois i acceptar les decisions preses en consens de cara a la pràctica de jocs.

- Valorar la riquesa patrimonial dels elements que es mantenen de la vila closa, i ser receptiu i sensible de cara a la seva preservació.

La metodologia es va desenvolupar en les següents fases:

\section{Fase prèvia}

Les sessions prèvies van anar encaminades a dissenyar l'estructura de la jornada.

- Vam acotar la zona de joc fent-la coincidir amb la teòrica muralla que, segons l'autor local Carmel Biarnés, envoltava el poble cap als segles XVI i $\mathrm{XVII}$, quan encara no havien estat expulsats els moriscs.

- Es va decidir fer l'activitat en divendres a la tarda a fi de poder comptar com a monitors amb l'alumnat d'Ascó que estudia ESO a l'IES Flix i que, aquest dia, no té classe a la tarda. El mestre d'Educació Física de l'IES va encarregar-se de proposar l'activitat a aquells nois explicant-los que cada grup de tres es responsabilitzaria d'una zona de joc. 


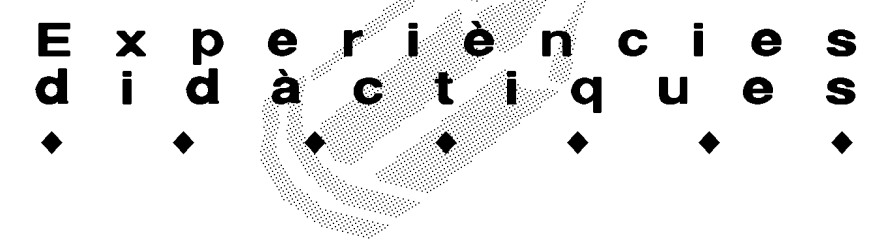

- Es van escollir quatre espais - places- en cadascun dels quals s'hi faria un o més jocs.

- Vam seleccionar els jocs que es practicarien escollint-ne alguns que ja coneixien a fi que, un cop es juguessin a l'indret preestablert, poguessin valorar la importància del context en el joc. I d'altra banda, vam preparar-ne uns altres que prèviament els nens del CEIP no coneixerien, $i$ que serien els alumnes de l'IES els encarregats d'ensenyar i guiar. Amb aquesta iniciativa aconseguíem crear expectativa entre els dos grups d'alumnes de nivells diferents, així com atorgar el protagonisme necessari als d'ESO, responsabilitzant-se del seu racó de joc.

Entre els jocs previstos n'hi havia que eren senzillament d'habilitat, de distracció; i d'altres de competitius entre els mateixos nens del grup -en aquests casos els nens guanyarien o perdrien patacons (a l'IES Flix els nostres alumnes saben fer patacons i coneixen diferents jocs amb ells. A més, els patacons els utilitzem en les apostes o en concepte de guany o pagament en un joc determinat com ara les bales, la rebelluga...).

- La mestra d'Educació Física del CEIP va fer grups de 7 i 8 nens, mixtos, tenint cura de barrejar els nens de $1 \mathrm{r}$ i $2 \mathrm{n}$ de CS. Es van fer, doncs, quatre grups. Va explicar com es desenvoluparia l'experiència, i va presentar els materials elaborats.

\section{Desenvolupament}

- El divendres 23 de maig, a les 14:55, els quatre grups estaven preparats al pla de l'església. Se'ls va explicar de nou, breument, la dinàmica de l'activitat. A cada grup es va donar un full guia i un plànol amb el recorregut que hauria de fer, passant estrictament pels carrers proposats. El grup, en tot moment, aniria junt $\mathrm{i}$ no s'iniciaria cap joc mentre tots els membres no haguessin arribat a l'espai de joc -amb això volíem deixar ben clar que no es tractava d'una cursa, sinó d'una mena de descoberta del nucli antic on l'observació i l'atenció tenien un pes important.

- Mentre s'anava d'una plaça a una altra es farien senzilles proves d'observació relacionades amb el patrimoni urbà, en les quals caldria estar molt atent.

- En cada zona disposarien d'un temps límit de 20 minuts per practicar cada joc i, després, de 5 minuts per desplaçar-se a la següent estació. Un cop es finalitzés tot el recorregut, ens reunírem de nou al pla de l'església per fer el recompte de patacons i fer els darrers jocs collectius que s'havien previst.

\section{Fase final}

- Per acabar el projecte vam dedicar una darrera sessió a explicar en una fitxa els jocs apresos i fer-ne el dibuix corresponent. Aquest material, junt amb fotografies de la jornada, el vam penjar a la pàgina web del centre (http://www.xtec.es/ ceipsantmiquel/Pagines/Experiencies/joc_a_joc/ index.htm).

\section{Estacions de joc, places de joc}

Es va dissenyar un itinerari en el qual els alumnes, partint des del pla de l'Església -el centre de la vilaanirien a quatre places distants no més de cinc minuts, $\mathrm{i}$ després farien el recorregut de plaça a plaça en el sentit contrari de les busques del rellotge. Les places escollides van ser el pla de Vallxiqué, l'hort de l'Abadia, cal Cavallé i el pla del carrer Valero (vegeu la figura 1).

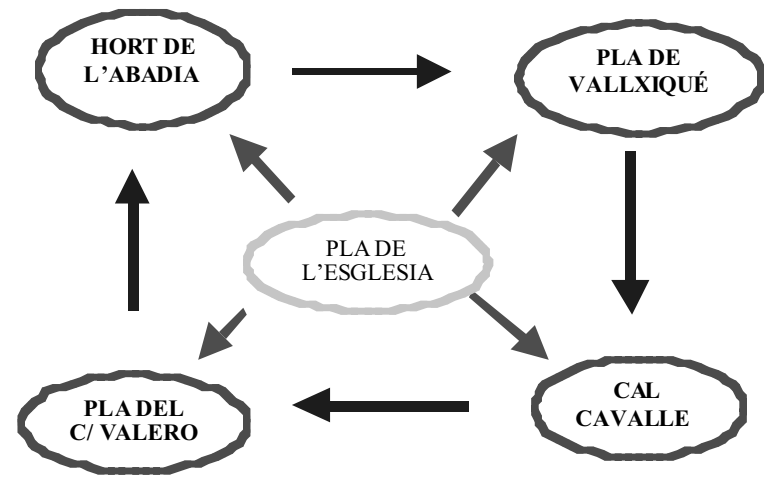

Figura 1. Itinerari seguit durant els jocs

\section{Jocs i activitats a les places}

Tirada de birles al pla del c/ Valero

Com hi juguem? Cada jugador disposa de 3 birlots per intentar tombar les 6 birles. La puntuació per cada birla caiguda és la següent:

1 birla $=1$ punt. 2 birles $=2$ punts. 3 birles $=3$ punts. 4 birles $=4$ punts. 5 birles $=10$ punts. 6 birles $=0$ punts (llenya!).

\section{Cavallé}

Tirada de rebellugues i flèndit de patacons a cal

El joc del roll o flènditera habitual a mitjans de segle passat, en particular entre els nens del poble, que es jugaven santets, cromos o patacons en cada tirada. A principis de segle hi jugaven també els adults, amb diners.

Com juguem al flèndit. Cada jugador disposarà de tres rolls que llançarà contra un petit canut damunt el qual hi haurà un nombre determinat de patacons. El canut estarà al centre d'una circumferència d'un parell de pams de radi. Si en llançar el roll aquest toca el canut 


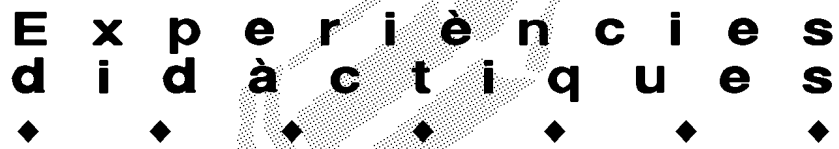

i fa volar els patacons que van a parar fora de la circumferència i, a més, el roll no queda dins d'aquesta, es guanyen tots els patacons que hagin sortit de la rotllana. Si en llançar el roll aquest toca el canut i fa volar els patacons fora de la circumferència però el roll resta a dins d'aquesta, no es guanya res. En cas que es llancin tres rolls i no s'encerti, es perd el torn. Es guanyen tants patacons com surten de la circumferència.

\section{La taula o planta de l'església, a l'hort de l'Abadia}

Es tracta, també, d'un joc típic de taverna, de bar, on la gent s'hi jugava el beure.

La forma de la taula ens recorda la planta d'una església -d'aquí el seu nom-, amb una nau principal i unes capelles o naus laterals. Com és lògic, la zona que correspondria a l'absis o altar té major puntuació que no pas la porta d'entrada.

Com hi juguem: Cada jugador disposa de 10 fitxes que intentarà fer entrar en algun dels forats del taulell de

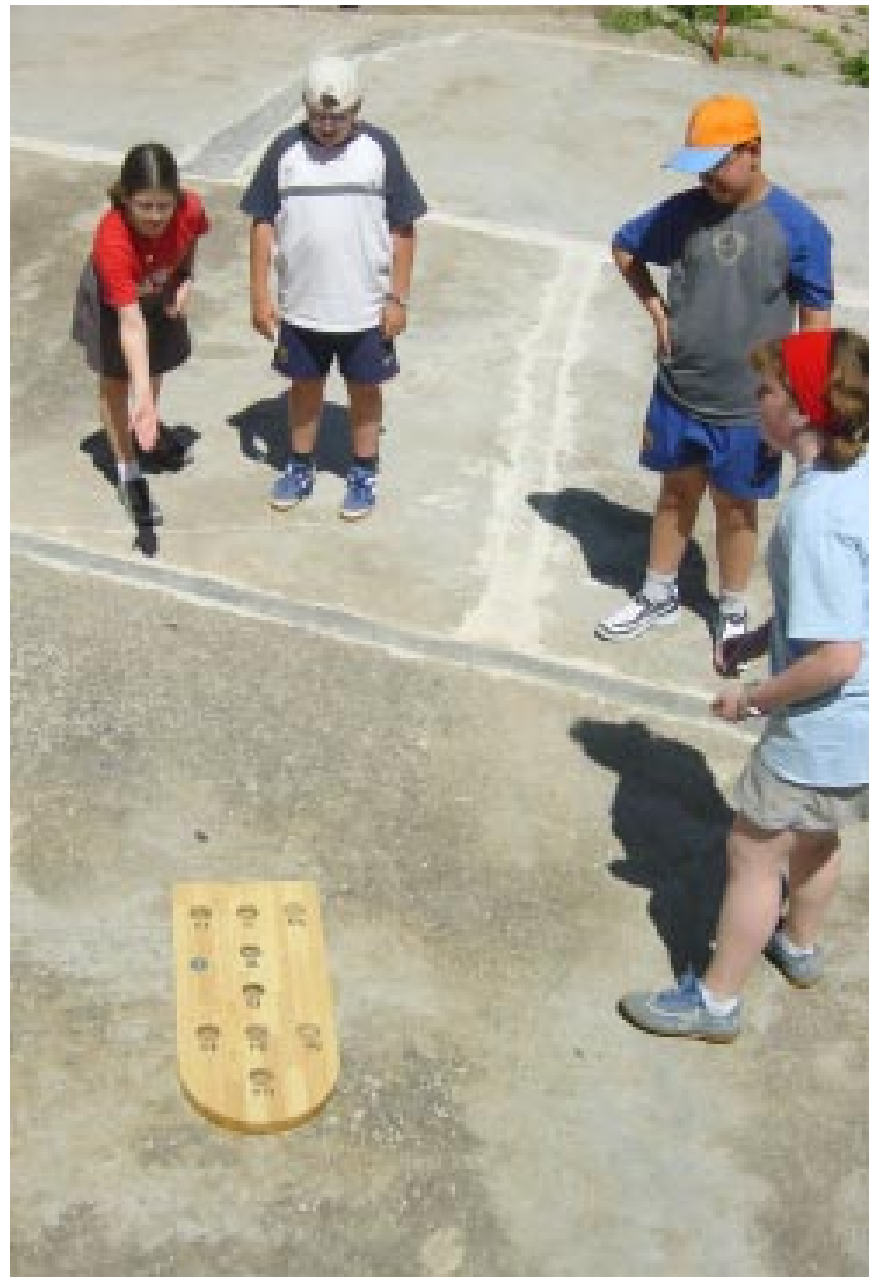

Joc de la taula o planta de l'església, a l'hort de l'Abadia. joc. La puntuació ve marcada sobre la planta de l'església.

\section{La rana a l'hort de l'Abadia}

És un joc molt antic. Egipcis, grecs i romans ja jugaven a algunes varietats d'aquest joc col-locant a una alçada determinada una àmfora el contingut de la qual acabaven de beure. Aleshores intentaven introduir dintre unes petites pedres. Qui no ho aconseguia perdia i havia de pagar el beure.

El segle XVIII fou un joc molt estès per tota Europa. Durant el segle passat fou molt conegut per Espanya, en particular a Castella i zones d'Aragó, especialment del Pirineu.

Durant la dècada dels anys cinquanta i també seixanta era joc habitual a l'entrada de bars i tavernes; hi havia el costum de jugar-se el beure entre els que hi feien cap.

Avui dia aquest joc és considerat un esport, ja que té unes regles i unes normes fixes.

Com hi juguem: Cada jugador disposa de 10 fitxes que intentarà fer entrar en algun dels forats del taulell de joc.

La puntuació és la següent:

Rana $=100$ punts. Molí $=50$ punts. Ponts $=25$ punts. Forats $=5$ punts.

Joc de la trisella a l'Hort de l'Abadia

Del joc de la trisella ja ens en parla Carmel Biarnés a l'apartat de jocs de la Guia d'Ascó. Dolors Cabré, en el llibre Riba-roja d'Ebre i el seu terme, fa referència també a un joc que anomena de la trigella o de la bola, però no indica com es desenvolupa.

El veí d'Ascó Antonio Ribes Ferrer, de 81 anys, recorda haver vist jugar a la trisella, i ens diu: "La trisella era una fusta, com un calaixó, que es feia servir per treballar amb los animals, per a portar terra. s'enganxava al collar dels animals i s'arrossegava la terra. El joc de la trisella tenia uns forats i es tenia de tirar la bola i encertar els forats. N'hi havia que la tenien a cal Sac, allà dalt a la Figuereta. Només hi volien jugar els més grans perquè... perquè els més petits fèiem nosa".

Mariano Vallès Biarnés, de 92 anys, també recorda el joc i explica que s'hi jugava al fossar vell i a l'era de l'Esquerré. Diu que en el joc de la trisella s'hi casava cèntims (es jugaven diners).

A Riba-roja, el senyor Agustí Agustí Cervelló, de 105 anys, confirmà exactament els comentaris anteriors, explicant-nos que ell hi havia arribat a jugar. L'anomena joc de trigella o de la bola, i diu que era un joc d'aposta en el qual dos jugadors s'apostaven diners. Des d'una distància de dos a tres metres s'havia de tirar la bola i si queia en un forat de color negre es guanyava; si queia en un forat roig, es perdia. Es podia jugar a un determinat nombre de tirades o bé, simplement, a una. 


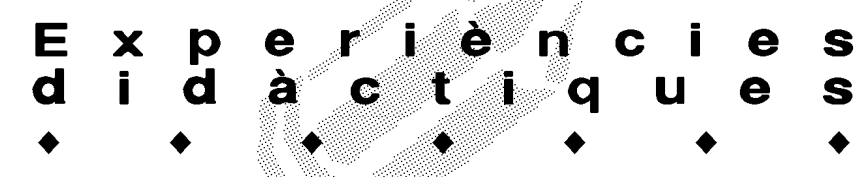

Com hi juguem: Cada jugador té cinc boles de fusta. Des d'una distància d'uns 2 metres intentarà introduir una bola als forats negres.

La puntuació per cada bola que s'entra als forats negres, serà: 2 boles $=3$ patacons. 3 boles $=5$ patacons. 4 boles $=8$ patacons. 5 boles $=10$ patacons.

Per cada bola entrada en un forat roig es descompten 2 patacons.

A/ set i mig amb roll i a lo cau, al pla de Vallxiqué

$\mathrm{El}$ joc del cau té els seus orígens en qualsevol dels jocs de bales que es practicaven des de l'antic Egipte, passant per la Grècia i Roma clàssiques.

En nombroses tombes d'aleshores $i$ en restes arqueològiques diverses -com ara el fòrum de Roma-, s'han trobat bales de materials diversos (pedra, marbre, vidre, os...).

Avui els principals centres productors de bales del món es troben a Alemanya i Mèxic.

Com juguem a Lo cau: En tractar-se d'un joc sobredimensionat, jugarem amb pilotes petites. Cada jugador disposarà de 8 pilotes que intentarà fer passar per les portetes (forats) del joc. Cada porta té, segons la seva grandària i dificultat, una puntuació diferent.

Jocs i activitats de cloenda al pla de l'Església

A les 16:50, seguint l'horari previst, ens vam trobar tots novament al pla de l'Església i vam acabar la tarda fent una estirada de corda i una correguda de sacs.

\section{Conclusions}

La valoració de l'activitat va resultar del tot positiva. Vam aconseguir involucrar en el projecte no sols tot l'alumnat de CS del CEIP d'Ascó, sinó també exalumnes que cursen estudis a l'IES de Flix, més de 50 xiquets.

A més, l'expectativa creada en el poble va generar un seguit d'actuacions destacades, com ara l'enregistrament en vídeo de tota l'activitat, o el ressò i els comentaris que molts veïns feien explicant als xiquets com i amb què jugaven abans o a quins llocs, així com descobrint les preguntes que havien de cercar fent-los adonar, aleshores, del valor patrimonial que té qualsevol petit detall de les construccions o del paisatge urbà.

Val a dir que es va comptar també amb la complicitat de l'Associació Cultural Lo Llaüt d'Ascó, que va cedir alguns dels jocs (birles, trisella, rana, tabla) i va col-laborar en el seguiment i control de l'activitat.

Som conscients que el projecte que hem presentat pot tenir dificultats d'aplicació en alguns contexts urbans on principalment els problemes de trànsit i les barreres arquitectòniques poden obstaculitzar la dinàmica referida. Tanmateix, pensem que el disseny d'activitats d'aquest tipus permet actuacions molt atractives i estimulants per als alumnes, que aprenen així a observar i a desxifrar més i millor el paisatge urbà i a valorar un patrimoni que massa sovint tenim oblidat. D'altra banda, el fet de poder treballar amb companys d'altres centres resulta enriquidor tant per als alumnes involucrats com per als professionals de l'ensenyament, amb un clar acostament que permet comprendre millor les dificultats dels altres $\mathrm{i}$ saber apreciar allò que tenim a l'abast.

Un consell, si teniu una mica d'empenta i hi veieu el fil... no ho dubteu, dissenyeu el vostre Joc a joc, de plaça a plaça.

\section{Referències bibliogràfiques}

BIARNÉS BIARNÉS, Carmel: Els moriscos a Catalunya. Apunts d'história d'Ascó. Gràfiques Moncunill, Valls, 1981.

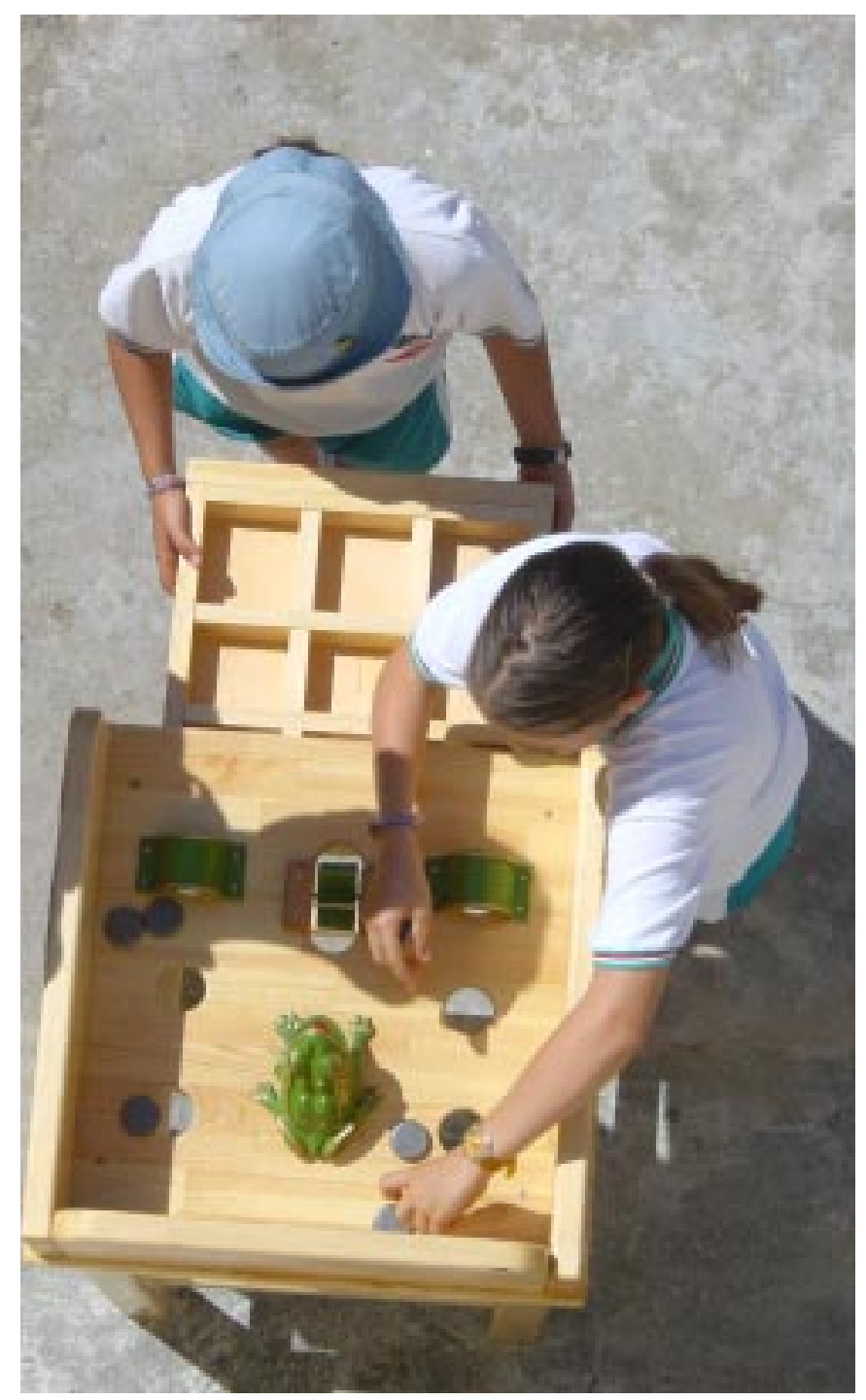

Joc de la rana, a l'hort de l'Abadia 